\title{
INVESTIGATING THE CRITICAL DETERMINANTS OF TRUST AND THEIR IMPACT ON MOBILE PAYMENT ADOPTION
}

\author{
Tuan Anh Nguyen ${ }^{1,2}$, Martin Dick ${ }^{1}$ and Hiep Cong Pham ${ }^{3}$

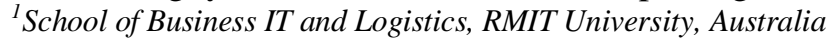 \\ ${ }^{2}$ Faculty of Information Technology, National Academy of Education Management \\ ${ }^{3}$ School of Business \& Management, RMIT University, Australia
}

\begin{abstract}
This study proposes a model investigating the critical determinants for trust, and the impact of trust on mobile payment adoption. This research aims to address the importance of trust in m-payment adoption, and overcome the limitations of previous studies which are a lack of understanding of the determinants of trust in m-payment adoption, a lack of adopting trust as a multi-dimensional construct, and a lack of consideration of the moderating role of culture. In this research, the authors employ the Unified Theory of Acceptance and Use of Technology, Siau and Shen's framework for building consumer trust in mobile commerce, and Hofstede's cultural framework as the theoretical basis. The proposed model encompasses four types of trust including mobile payment provider trust, mobile technology trust, institution-based trust, and seller trust, which are well-defined in the related literature, and a moderating role for culture between the four types of trust and mobile payment adoption. The model of the study not only may be used to improve understanding of trust in mobile payment adoption, but also contribute to the literature of the determinants for trust in mobile payment adoption.
\end{abstract}

\section{KEYWORDS}

Mobile Payment, Mobile Payment Adoption, Mobile Payment Acceptance, Trust, Mobile Payment Use

\section{INTRODUCTION}

Mobile payment (m-payment) refers to financial transactions made via mobile devices (Stringfellow 2018). Simply, m-payment users can use mobile devices to pay for goods or services that they purchase online or offline. Remote m-payment is implemented from a distance, without direct interaction between buyers and sellers or the merchants' point of sale systems (POS). Common examples of remote m-payment are carrier billing, short message service (SMS) payments or using mobile phones to pay directly via applications such as Paypal. In contrast, the proximity m-payment method based on Near Field Communications (NFC) allows customers to use their mobiles phones via Apple Pay, Samsung Pay or Google Pay functions to interact with a seller's POS to pay. Mobile payment is considered as the newest means of payment in the evolution of payment methods based on the Internet and mobile devices (Kolaki 2017). Global use of m-payment is predicted to rise $28 \%$ by 2022 , and surpass cash and credit cards, therefore m-payment will contribute to bringing societies towards the future of a cashless world (MerchantSavvy 2019).

Many studies have found that trust has a significant positive influence on consumers' intention to adopt m-payment (Andreev, Pliskin \& Rafaeli 2012; Liu 2012). However, little attention has been paid to which factors are the critical determinants for m-payment trust (Patil et al. 2018). As well, trust is often regarded as a single construct in previous studies when trust is a complex phenomenon and a better understanding of trust dimensions in m-payment adoption can better predict adoption and potentially use patterns (Meng, Min \& $\mathrm{Li}$ 2008). Another factor is culture which often plays a crucial role in consumer technology adoption because it may cause and explain a discrepancy in consumer behaviour in acceptance or intention to adopt a new system or technology (Choi et al. 2014). Hofstede's cultural dimensions is one of the most frequent cultural frameworks used in culture research (Eringa et al. 2015). Many studies have found a significant moderating role of Hofstede's cultural dimensions on the consumer adoption of a system or technology (Baptista \& Oliveira 2015; Yoon 2009). Nonetheless, the moderating role of Hofstede cultural dimensions have not yet been 
examined in m-payment adoption, therefore, it is likely to be productive to address it.

Consequently, this study aims to identify the critical determinants for a multi-dimensional model of trust in relation to m-payment adoption including m-payment provider trust, technology trust, institution-based trust, and seller trust with a moderating effect of culture on each type of trust. The paper contributes to a more comprehensive understanding of trust's antecedents in m-payment adoption, and the impact of a multi-dimensional trust on m-payment adoption.

\section{LITERATURE REVIEW}

\subsection{Previous Studies Involved in Trust in m-Payment Adoption}

Trust is generally essential in any economic activity (Coyle 2013). A lack of trust has been historically found as a significant barrier to conducting any mobile commerce (m-commerce) services (Joubert \& Belle 2009). As a result, trust also plays an important role in m-payment adoption, and therefore, has received the attention of researchers.

Many studies have adopted the Technology Acceptance Model (TAM) or the Unified Theory of Acceptance and Use of Technology (UTAUT) as their theoretical framework and found a significant impact of trust on intention to adopt m-payment of consumers. When researching drivers of the willingness to use $\mathrm{m}$-payment in Israel, Andreev, Pliskin and Rafaeli (2012) extended TAM and included Diffusion of Innovation theory (DOI), and found a direct and significant impact of vendor trust, and a non-significant impact of mechanism trust on willingness to use m-payment. Phonthanukitithaworn, Sellitto and Fong (2015) extended TAM to test user intentions to adopt m-payment services in Thailand and found that perceived trust had a significant influence on behavioural intention. The study of Slade et al. (2015) based on UTAUT2, collected data in the UK, and revealed that trust is an important predictor for intention to adopt m-payment. Based on UTAUT and TAM, Qasim and Abu-Shanab (2016) examined the impact of network externalities including performance and effort expectancy, social influence, and trust on m-payment acceptance in Jordan. Data analysis revealed that except for effort expectancy, the important role of the other drivers was proven. Gao and Waechter (2017) integrated TAM and the Information System Success model (ISS) to argue that a lack of trust is the most significant long-term inhibitor for acceptance and success of m-payment, and examined the role of initial trust on perceived benefit and convenience which in turn influenced intention to adopt $\mathrm{m}$-payment. Gao and Waechter collected data from a sample in Australia, and revealed that perceived system quality, perceived uncertainty, information quality and service quality also positively and significantly influenced initial trust, which positively impacts on intention to adopt m-payment. In China, several studies also found that trust have a significant impact on m-payment adoption (Liu 2012; Mingxing, Jing \& Yafang 2014; Yan \& Yang 2014; Zhou 2011).

Besides TAM and UTAUT, several studies have adopted other theories and also found the important effect of trust on m-payment acceptance such as Lu et al. (2011) using the valence framework; and Jia, Hall and Zhu (2015) utilising a multi-stage decision making model and initial trust building theory. Zhou (2014) adopted the ISS model and identified the important effect of factors including trust on online payment, system quality, and information quality on trust in m-payment, which significantly influences continuance usage of m-payment. Xin, Techatassanasoontorn and Tan (2015) collected data in New Zealand and suggested a model of antecedents of trust in m-payment. This model encompasses five groups of factors: characteristics of the mobile service provider including perceived reputation of mobile service provider and perceived opportunism of mobile service provider, characteristics of the mobile payment provider including perceived reputation of mobile payment vendor and perceived opportunism of mobile payment vendor, characteristics of mobile technology including perceived structural assurance and perceived environmental risk, a cultural variable which is uncertainty avoidance, and a personality variable which is disposition to trust.

\subsection{Limitations of Existing Studies}

The literature review of m-payment adoption shows that trust is highly likely to be a vital driver for m-payment adoption from an individual or consumer perspective. However, the existing research on trust in m-payment adoption has largely investigated the influence of trust on the consumer intention to adopt m-payment, while 
little attention has been paid to explore determining factors of m-payment trust (Patil et al. 2018). As a result, research on factors which can be employed as determinants for trust in m-payment adoption needs to be empirically investigated further.

Another limitation of existing research on m-payment trust and its adoption is the lack of investigation of moderating variables between trust and m-payment adoption. A moderating variable plays an important role in psychological or behavioural research because it can enhance or reduce the magnitude of the relationship between a predictor and an outcome (Lani 2018). Undoubtedly, the role of moderating variables should be evaluated to provide a comprehensive understanding of the impact of trust on customer intention to adopt m-payment. Culture is defined as the "collective programming of the mind which distinguishes the members of one group or category of people from those of another" (Hofstede 1993, p. 4). Many studies have been conducted to test the significant moderating impact of Hofstede's cultural dimensions on intention of consumers to adopt a new system or technology (Baptista \& Oliveira 2015; Yoon 2009). However, an examination of the moderating role of culture between trust and the use of m-payment has not yet been performed. As a result, an investigation of the moderating impact of culture on the relationship between trust and consumers' $m$-payment adoption is necessary and significant.

Finally, trust is considered a complex concept, thus, it should be modelled as a multifaceted phenomenon (Jimenez, San-Martin \& Azuela 2016; McKnight, Choudhury \& Kacmar 2002; Meng, Min \& Li 2008). However, most existing research on m-payment trust models trust as a single construct. Researchers have pointed out that exploring different types of trust in m-commerce can achieve a better understanding of consumer trust, which has a significant impact on understanding and predicting consumer adoption (Meng, Min \& Li 2008). Accordingly, research on trust in m-payment adoption needs to distinguish the different types of trust. This is necessary to acquire a clear understanding of how each type of trust can influence m-payment adoption.

\subsection{Research Aims and Questions}

The main objective of this research is to investigate the critical determinants of trust, and the moderating effect of culture in the relationship between trust and m-payment adoption. Particularly, it aims to answer:

- What are the types of trust in the m-payment context?

- To what extent does each type of trust influence consumer's m-payment adoption?

- What are the critical determinants for consumers' trust in m-payment adoption?

- To what extent does culture moderate the impact of trust on m-payment adoption?

\section{A CONCEPTUAL MODEL}

\subsection{Theoretical Background}

UTAUT was formulated based on unifying eight prominent models in technology adoption area which are the Theory of Reasoned Action, TAM, the Motivational Model, the Theory of Planned Behaviour (TPB), the combined TAM and TPB, the Model of PC Utilization, Diffusion of Innovation theory, and Social Cognitive Theory (Venkatesh et al. 2003; Venkatesh, Thong \& Xu 2012). Accordingly, this model covers most variables necessary to study technology acceptance or behavioural intention to adopt a new system (Qasim \& Abu-Shanab 2016). In addition, after collecting data for six months from four organisations, the analysis outcome revealed that UTAUT has an adjusted $\mathrm{R}^{2}$ of 69 per cent, which outperforms the eight previous models (Venkatesh et al. 2003). Since its appearance, UTAUT has been widely and successfully adopted as a theoretical lens in a large number of studies of technology adoption or acceptance (Williams, Rana \& Dwivedi 2015). Consequently, the authors adopt UTAUT as a theoretical background in this research.

The authors also adapt consumer trust in m-commerce from Siau and Shen's framework (2003) which posits that general consumer trust is based on mobile technology trust and mobile vendor trust because $\mathrm{m}$-payment is considered as a subset of m-commerce. Applying Siau and Shen's framework to the context of m-payment, the vendor is not the seller or merchant, but should be the m-payment provider who provides m-payment service for consumers (Srivastava, Chandra \& Theng 2010). 
Hofstede's framework on culture is employed to hypothesise the moderating role of cultural variables between trust and m-payment adoption. Hofstede analysed the characteristics of culture around the world, and suggested five dimensions of natural culture, which are power distance, individualism/collectivism, uncertainty avoidance, masculine/feminine, and long-term/short-term orientation. Hofstede's cultural framework is one of the most important and influencing cultural studies which have been adopted widely in research in technology adoption (Baptista \& Oliveira 2015).

Furthermore, a comprehensive review of related literature regarding the determinants of consumer trust in the adoption of e-commerce, m-commerce, mobile banking, and m-payment was conducted to support the background and hypotheses of this research. This is because: (1) m-payment is consider as an accelerator of payment method for m-commerce as well as e-commerce (Kumar 2013), i.e. m-payment is a subset of $\mathrm{m}$-commerce as well as e-commerce, and mobile banking applications also can provide the payment functions; (2) there is no consensus and consistency of antecedents of trust in m-payment adoption due to a very limited numbers of studies in the literature. Obviously, a comprehensive review of related literature is necessary and significant.

\subsection{The Proposed Conceptual Model and Hypotheses}

Based on the comprehensive of related literature review of trust, four types of trust for m-payment adoption are proposed in this study.

(1) M-payment provider trust refers to the belief of consumers that the m-payment service provider will perform and complete the transaction even if there are risky or uncertain circumstances (Joubert \& Belle 2009, 2013). Simply, m-payment provider trust indicates whether the provider of m-payment service can be trusted by customers or consumers using m-payment. Mingxing, Jing and Yafang (2014) highlighted the significance of m-payment service provider trust because it represents the extent to which users believe that a service provider can implement m-payment service correctly, fast, conveniently, and safely. Many authors also recognised the significant impact of service providers' roles on trust of consumers in m-commerce and m-payment adoption (Min, Meng \& Zhong 2008; Xin, Techatassanasoontorn \& Tan 2015). As a result, the authors argue that if consumers perceive that an m-payment provider is trustworthy, they are more likely to adopt m-payment.

(2) Technology trust or system trust refers to the degree to which the consumer believes that the underlying technology or system has the ability to work as expected and to process an m-payment transaction appropriately (Joubert \& Belle 2013). This research focuses on the consumer perspective of system/technology trust, instead of the viewpoint of technical experts. Technology trust is another vital aspect of trust which has been adopted in various studies on technology or system adoption in e-commerce, m-commerce and m-payment (Joubert \& Belle 2009, 2013; Min, Meng \& Zhong 2008; Pennington, Wilcox \& Grover 2003; Siau \& Shen 2003; Srivastava, Chandra \& Theng 2010). As a result, the authors argue that if consumers perceive that the underlying m-payment technology is trustworthy, they are more likely to adopt m-payment.

(3) Institution-based trust is the belief of consumers that necessary structural conditions for increasing the likelihood of gaining a successful outcome in an endeavour like m-payment, are present (McKnight, Choudhury \& Kacmar 2002). These structural conditions are related to laws, regulations, institutions, legal protection, and the legal system, which contribute to the feelings of trustworthiness of an environment. Many researchers highlight that trust cannot be built without institutional infrastructures that set up and consolidate regulations in m-commerce and m-payment (Joubert \& Belle 2009; McKnight, Choudhury \& Kacmar 2002). Due to the importance of institution-based trust, many authors have employed it in research on e-commerce and m-commerce adoption (McKnight, Choudhury \& Kacmar 2002; Min, Meng \& Zhong 2008). As a result, the authors argue that if consumers perceive that they are protected by the third-party institutional mechanism, they are more likely to adopt m-payment.

(4) Seller trust is the degree to which the consumer trusts a community of sellers, and this is necessary for any e-commerce as well as social commercial activities (Lu, Fan \& Zhou 2016). Andreev, Pliskin and Rafaeli (2012) pointed out that seller trust plays a vital role in $\mathrm{m}$-commerce where there is an anonymous contact between sellers and buyers and a lack of formal contractual agreement, and found the significant impact of seller trust on willingness to accept m-payment of customers. Seller trust is adopted in many studies on e-commerce as well as m-payment adoption (Andreev, Pliskin \& Rafaeli 2012; Lu, Fan \& Zhou 2016; Pavlou $\&$ Gefen 2004). Obviously, a reputable seller must not only provide qualified goods, but also use a fast, accurate 
and secured payment method. As a result, if customers trust reputable sellers accepting m-payment, customers are more likely to adopt m-payment.

The authors adopt these four types of trust for m-payment adoption, and propose the hypotheses below:

- H1,2,3,4: M-payment provider trust, technology trust, institution-based trust, and seller trust positively influence m-payment adoption.

Performance expectancy (PE) "is defined as the degree to which an individual believes that using the system will help him or her to attain gains in job performance" (Venkatesh et al. 2003, p. 447). The significant impact of PE on consumers' trust has been proven through many studies in e-commerce, m-commerce, and m-payment adoption (Li \& Yeh 2010; Lin et al. 2014; Yan \& Pan 2014; Yan \& Yang 2014; Zhou 2011). As a result, the authors argue that if consumers perceive the usefulness or performance of m-payment, they may be more likely to trust m-payment technology and m-payment providers. This leads to the hypotheses:

- H5,6: Performance expectancy positively influences m-payment provider trust and technology trust.

Effort expectancy (EE) "is defined as the degree of ease associated with the use of the system" (Venkatesh et al. 2003, p. 450). Many studies in e-commerce, m-commerce, and m-payment have found that EE has significant impact on consumers' trust (Li \& Yeh 2010; Yan \& Pan 2014; Yan \& Yang 2014; Zhou 2011). An easy to use m-payment application may reflect the ability and reliability of a m-payment provider and underlying technology. As a result, the authors argue that EE has a significant impact on m-payment provider trust and technology trust. This leads to the hypotheses:

- H7,8: Effort expectancy positively influences m-payment provider trust and technology trust.

Social influence (SI) is defined as "the degree to which an individual perceives that important others believe he or she should use the new system" (Venkatesh et al. 2003, p. 451). Basically, it conveys a notion that an individual's perception of society's expectations influences their behaviour. SI has been found to be an important driver for consumer trust in the adoption of mobile banking, online banking and e-commerce (Lu, Yao \& Yu 2005; Malaquias \& Hwang 2016; Montazemi \& Qahri-Saremi 2015), for building institution-based trust in organisations (Bachmann \& Inkpen 2011), and for seller trust in online shopping or e-commerce (Guo, Wang \& Leskovec 2011; Lu, Fan \& Zhou 2016; Pavlou \& Gefen 2004). If a person perceives that people important to him/her trust m-payment applications and want him/her to use these, he/she is likely to generally trust m-payment including m-payment provider and technology. Similarly, citizens tend to trust sellers who have a good reputation in society. In addition, if m-payment is popular and trustworthy to citizens, the legal institutions must control and manage m-payment in order to ensure the legal rights of m-payment customers, and legal operations involved in m-payment. As a result, the authors argue that SI has a significant impact on m-payment provider trust, technology trust, institutional-based trust and seller trust of consumers in m-payment adoption. This leads to the hypotheses:

- H9,10,11,12: Social influence positively affects m-payment provider trust, technology trust, institution-based trust, and seller trust.

Disposition to trust (DT) refers "the extent to which a person displays a tendency to be willing to depend on others across a broad spectrum of situations and persons" (McKnight, Choudhury \& Kacmar 2002, p. 339). The two studies of Joubert and Belle (2009) (2013) indicate the significant impact of DT on vendor trust, systems trust, and institutional-based trust of South African consumers in m-commerce adoption. McKnight, Choudhury and Kacmar (2002) identified the important effect of DT on institution-based trust when developing their web trust model of consumers in e-commerce. Meng, Min and Li (2008) suggested that DT has an important influence on mobile technology trust, mobile vendor trust, and institution-based trust. Pavlou and Gefen (2004) found out the significant impact of trust propensity on seller trust of e-commerce customers in Amazon's online auction marketplace. Lu, Fan and Zhou (2016) also recognised the important effect of DT on seller trust when researching trust and social commerce purchase intention in China. As a result, the authors argue that a person with high DT is more likely to have increased m-payment provider trust, technology trust, institutional-based trust, and seller trust in the adoption of m-payment. This leads to the hypotheses:

- H13,14,15,16: Disposition to trust influence positively affects m-payment provider trust, technology trust, institution-based trust, and seller trust.

Power distance (PD) reflects the inequality of power between managers and employees (Hofstede-insights 2018). In cultures with a high PD index, management decisions would be centralized and hierarchical, and people are more likely to comply with their managers' opinion. In contrast, in low PD societies, superiors and subordinates are more equal, therefore they are more interdependent. Interdependence is an important necessary condition for trust, therefore people in low PD societies tend to have more interpersonal trust than ones in high PD societies (Yoon 2009). Consequently, customers with high PD scores may have less trust toward m-payment adoption than ones with lower PD scores. This leads to the hypothesis: 
- H17. Power distance moderates the relationship between trust and m-payment adoption, in such a way that the relationship will be lower amongst people with higher power distance cultural values.

Cultures with a long-term orientation (LTO) index are oriented toward future achievements when dealing with the challenges of the present and the future (Hofstede-insights 2018). Citizens with high LTO scores may be more likely to adopt m-payment because they are more aware of the long-term benefits of m-payment. As a result, customers with high LTO scores may have more trust toward m-payment adoption. This leads to the hypothesis:

- H18. Long-term orientation moderates the relationship between trust and m-payment adoption, in such a way that the relationship will be stronger amongst people with long-term cultural values.

People in individualistic cultures are expected to be more focused on themselves than with the group while ones in collectivistic cultures are sensitive to the group boundary (Hofstede 1993). As a result, citizens in collectivistic societies appreciate trusting members in a group, and trust less people outside their in-group. In contrast, individualistic citizens find it easier meeting new people, and tend to be more willing to rely on strangers (Yoon 2009). Consequently, people with individualist index may be more likely to have trust toward m-payment adoption than collectivists. This leads to the hypothesis:

- H19. Individualism moderates the relationship between trust and m-payment adoption, in such a way that the relationship will be stronger amongst people with individualist cultural values.

"The Masculinity side of this dimension represents a preference in society for achievement, heroism, assertiveness, and material rewards for success" (Hofstede-insights 2018). In a society with masculinity index, citizens tend to appreciate challenges, earnings, assertiveness, ambition, and dealing with facts (Minkov $\&$ Hofstede, 2010). People with high masculinity scores tend to adopt m-payment because they are more likely to value the benefits of m-payment more highly. This leads to the hypothesis:

- H20. Masculinity moderates the relationship between trust and m-payment adoption, in such a way that the relationship will be stronger amongst people with masculine cultural values.

"The Uncertainty Avoidance dimension expresses the degree to which the members of a society feel uncomfortable with uncertainty and ambiguity" (Hofstede-insights 2018). Cultures with high levels of uncertainty avoidance (UA) usually feel scared in uncertain situations (Ford, Connelly \& Meister 2003). Consequently, citizens with high UA scores are expected to have a low rate of technology adoption and may have less trust toward m-payment adoption, because a new technology may be more risky than traditional payment methods. This leads to the hypothesis:

- H21. Uncertainty avoidance moderates the relationship between trust and m-payment adoption, in such a way that the relationship will be weaker among people with higher levels of uncertainty avoidance values.

Figure 1 below presents the overall model and the hypotheses.

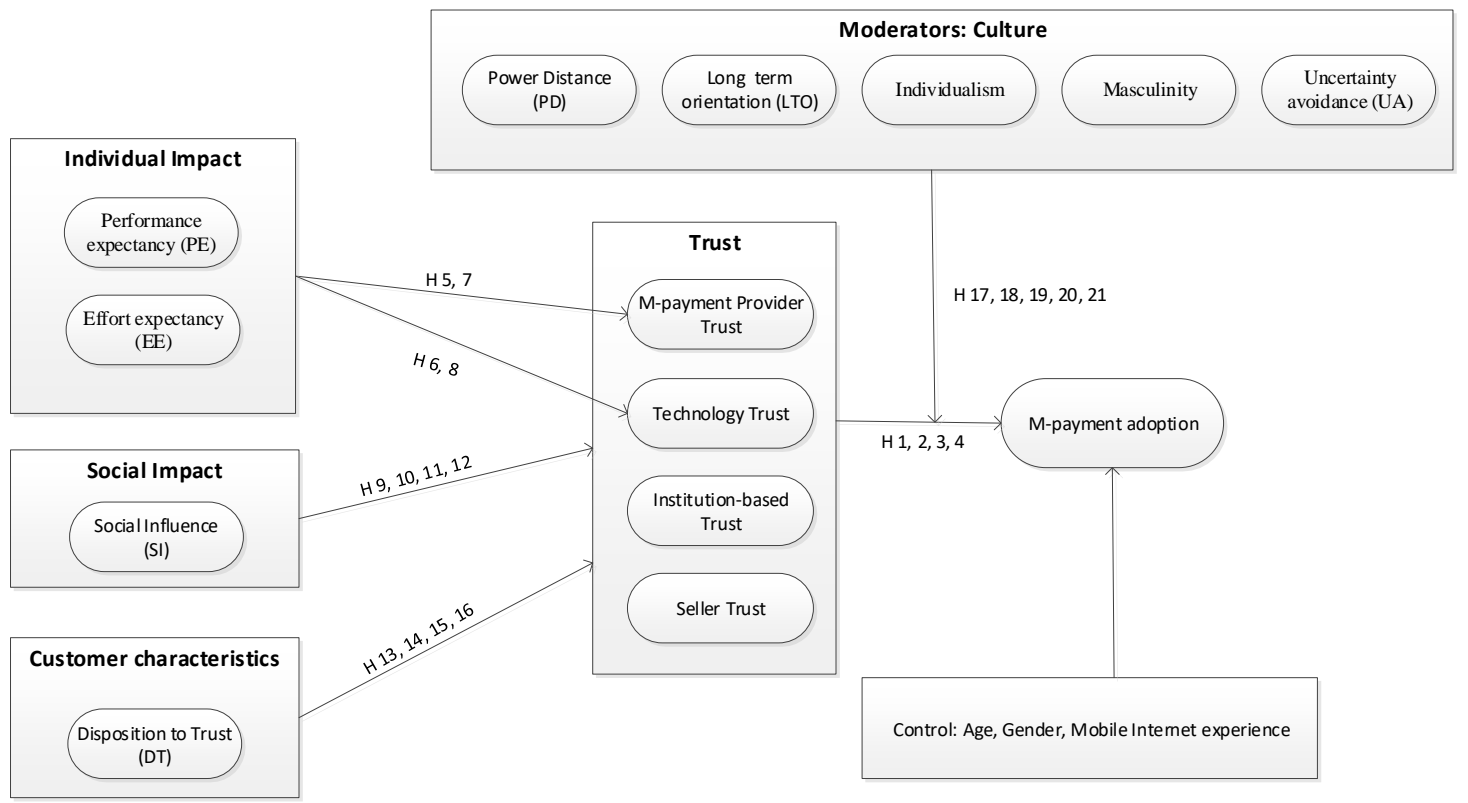

Figure 1. The conceptual model 


\section{CONCLUSION}

M-payment benefits consumers, as well as, business due to the convenience, security, easier managing and monitoring of transactions, and improvement of the customer experience. As a result, m-payment should be considered as a powerful tool for both consumers and business performance. This research aims to address the issue of lacking understanding of the determinants of trust in m-payment adoption, and theorises trust as a multi-dimensional construct, with the consideration of the moderating role of culture on the four types of trust. This paper proposes a more comprehensive model of the critical determinants for trust in m-payment adoption, which may lead to more understanding for organisations, policy makers, m-payment services providers, and consultants to improve consumer trust when adopting m-payment. The model will be tested via an online survey in Vietnam and will be analysed using Structural Equation Modelling (SEM).

\section{REFERENCES}

Andreev, P, Pliskin, N \& Rafaeli, S 2012, 'Drivers and inhibitors of mobile-payment adoption by smartphone users', International Journal of E-Business Research (IJEBR), vol. 8, no. 3, pp. 50-67.

Bachmann, R \& Inkpen, AC 2011, 'Understanding institutional-based trust building processes in inter-organizational relationships', Organization Studies, vol. 32, no. 2, pp. 281-301.

Baptista, G \& Oliveira, T 2015, 'Understanding mobile banking: The unified theory of acceptance and use of technology combined with cultural moderators', Computers in Human Behavior, vol. 50, pp. 418-430.

Choi, J, Lee, HJ, Sajjad, F \& Lee, H 2014, 'The influence of national culture on the attitude towards mobile recommender systems', Technological Forecasting and Social Change, vol. 86, pp. 65-79.

Coyle, D 2013, The cost of mistrust, OECD, viewed 14/12, <http://www.oecd.org/forum/the-cost-of-mistrust.htm>.

Eringa, K, Caudron, LN, Rieck, K, Xie, F \& Gerhardt, T 2015, 'How relevant are Hofstede's dimensions for inter-cultural studies? A replication of Hofstede's research among current international business students', Research in Hospitality Management, vol. 5, no. 2, pp. 187-198.

Ford, DP, Connelly, CE \& Meister, DB 2003, 'Information systems research and Hofstede's culture's consequences: an uneasy and incomplete partnership', vol. 50, no. 1, pp. 8-25.

Gao, L \& Waechter, KA 2017, 'Examining the role of initial trust in user adoption of mobile payment services: an empirical investigation', Information Systems Frontiers, vol. 19, no. 3, pp. 525-548.

Guo, S, Wang, M \& Leskovec, J 'The role of social networks in online shopping: information passing, price of trust, and consumer choice', ACM, pp. 157-166.

Hofstede-insights 2018, NATIONAL CULTURE, Hofstede-insights, viewed 27/12, <https://www.hofstedeinsights.com/models/national-culture/>.

Hofstede, GH 1993, 'Cultures and organizations, software of the mind', Administrative Science Quarterly, vol. 38, pp. 132-134.

Jia, L, Hall, D \& Zhu, S 2015, 'Trust building in consumer learning process and its effect on consumers' behavioral intention toward mobile payments', vol.

Jimenez, N, San-Martin, S \& Azuela, JI 2016, Trust and satisfaction: the keys to client loyalty in mobile commerce', Academia Revista Latinoamericana de Administración, vol. 29, no. 4, pp. 486-510.

Joubert, J \& Belle, J-PV 2009, 'The importance of trust and risk in M-commerce: A South African perspective', PACIS 2009 Proceedings, vol., p. 96.

Joubert, J \& Belle, J-PV 2013, 'The role of trust and risk in mobile commerce adoption within South Africa', International Journal of Business, Humanities and Technology, vol. 3, no. 2, pp. 27-38.

Kolaki, M 2017, 'Mobile Payment Use and Mobile Payment Transactions by Older Adults: A Qualitative Study', thesis.

Kumar, B 2013, 'A Study on Mobile payment in Mobile Commerce', International Journal of Enhanced Research in Management, vol., pp. 1-8.

Lani, J 2018, Moderator Variable, Statistics solutions, viewed 12/12, <https://www.statisticssolutions.com/directory-ofstatistical-analyses-general-moderator-variable/>.

Li, Y-M \& Yeh, Y-S 2010, 'Increasing trust in mobile commerce through design aesthetics', Computers in Human Behavior, vol. 26, no. 4, pp. 673-684.

Lin, J, Wang, B, Wang, N \& Lu, Y 2014, 'Understanding the evolution of consumer trust in mobile commerce: a longitudinal study', Information Technology and Management, vol. 15, no. 1, pp. 37-49. 
Liu, B 'Understanding Consumers' Intention to Use Mobile Payment Services: The Perspective of University Students in Northern Jiangsu Area', IEEE, pp. 257-260.

Lu, B, Fan, W \& Zhou, M 2016, 'Social presence, trust, and social commerce purchase intention: An empirical research', Computers in Human Behavior, vol. 56, pp. 225-237.

Lu, J, Yao, JE \& Yu, C-S 2005, 'Personal innovativeness, social influences and adoption of wireless Internet services via mobile technology', The Journal of Strategic Information Systems, vol. 14, no. 3, pp. 245-268.

Lu, Y, Yang, S, Chau, PY \& Cao, Y 2011, 'Dynamics between the trust transfer process and intention to use mobile payment services: A cross-environment perspective', Information \& Management, vol. 48, no. 8, pp. 393-403.

Malaquias, RF \& Hwang, Y 2016, 'An empirical study on trust in mobile banking: A developing country perspective', Computers in Human Behavior, vol. 54, pp. 453-461.

McKnight, DH, Choudhury, V \& Kacmar, C 2002, 'Developing and validating trust measures for e-commerce: An integrative typology', Information systems research, vol. 13, no. 3, pp. 334-359.

Meng, D, Min, Q \& Li, Y 'Study on trust in mobile commerce adoption-a conceptual model', IEEE, pp. 246-249.

MerchantSavvy 2019, 30 Amazing Stats Demonstrating The Unstoppable Rise of Mobile Payments Globally, $<$ https://www.merchantsavvy.co.uk/mobile-payment-stats-trends/>.

Min, Q, Meng, D \& Zhong, Q 'An empirical study on trust in mobile commerce adoption', IEEE, pp. 659-664.

Mingxing, S, Jing, F \& Yafang, L 'An empirical study on consumer acceptance of mobile payment based on the perceived risk and trust', IEEE, pp. 312-317.

Montazemi, AR \& Qahri-Saremi, H 2015, 'Factors affecting adoption of online banking: A meta-analytic structural equation modeling study', Information \& Management, vol. 52, no. 2, pp. 210-226.

Patil, P, Rana, N, Dwivedi, Y \& Abu-Hamour, H 'The role of trust and risk in mobile payments adoption: a meta-analytic review',

Pavlou, PA \& Gefen, D 2004, 'Building effective online marketplaces with institution-based trust', Information systems research, vol. 15, no. 1, pp. 37-59.

Pennington, R, Wilcox, HD \& Grover, V 2003, 'The role of system trust in business-to-consumer transactions', Journal of management information systems, vol. 20, no. 3, pp. 197-226.

Phonthanukitithaworn, C, Sellitto, C \& Fong, M 2015, 'User intentions to adopt mobile payment services: A study of early adopters in Thailand', Journal of internet Banking and Commerce, vol. 20, no. 1.

Qasim, H \& Abu-Shanab, E 2016, Drivers of mobile payment acceptance: The impact of network externalities', Information Systems Frontiers, vol. 18, no. 5, pp. 1021-1034.

Siau, K \& Shen, Z 2003, 'Building customer trust in mobile commerce', Communications of the ACM, vol. 46, no. 4, pp. 91-94.

Slade, E, Williams, M, Dwivedi, Y \& Piercy, N 2015, 'Exploring consumer adoption of proximity mobile payments', Journal of Strategic Marketing, vol. 23, no. 3, pp. 209-223.

Srivastava, SC, Chandra, S \& Theng, Y-L 2010, 'Evaluating the role of trust in consumer adoption of mobile payment systems: An empirical analysis', Communications of the Association for Information Systems, vol. 27, pp. 561-588.

Stringfellow, A 2018, What is a mobile payment?, viewed 3/01, <https://www.tccrocks.com/blog/what-is-a-mobilepayment/>.

Venkatesh, V, Morris, MG, Davis, GB \& Davis, FD 2003, 'User acceptance of information technology: Toward a unified view', MIS quarterly, vol., pp. 425-478.

Venkatesh, V, Thong, JY \& Xu, X 2012, 'Consumer acceptance and use of information technology: extending the unified theory of acceptance and use of technology', MIS quarterly, vol., pp. 157-178.

Williams, MD, Rana, NP \& Dwivedi, YK 2015, The unified theory of acceptance and use of technology (UTAUT): a literature review', vol. 28, no. 3, pp. 443-488.

Xin, H, Techatassanasoontorn, AA \& Tan, FB 2015, 'Antecedents of consumer trust in mobile payment adoption', Journal of Computer Information Systems, vol. 55, no. 4, pp. 1-10.

Yan, H \& Pan, K 'Examine User Adoption of Mobile Payment Using the TAM: A Trust Transfer Perspective', p. 55.

Yan, H \& Yang, Z 'An Empirical Examination of User Adoption Mobile Payment', IEEE, pp. 156-162.

Yoon, C 2009, 'The effects of national culture values on consumer acceptance of e-commerce: Online shoppers in China', Information \& Management, vol. 46, no. 5, pp. 294-301.

Zhou, T 2011, 'The effect of initial trust on user adoption of mobile payment', Information Development, vol. 27, no. 4, pp. 290-300.

Zhou, T 2014, 'Understanding the determinants of mobile payment continuance usage', Industrial Management \& Data Systems, vol. 114, no. 6, pp. 936-948. 